Article

\title{
Reversing Poor Safety Records: Identifying Best Practices to Improve Fleet Safety
}

\author{
Matthew C. Camden*(D), Jeffrey S. Hickman and Richard J. Hanowski \\ Virginia Tech Transportation Institute, Virginia Tech, Blacksburg, VA 24061, USA; jehickma@vt.edu (J.S.H.); \\ rhanowski@vtti.vt.edu (R.J.H.) \\ * Correspondence: mcamden@vtti.vt.edu; Tel.: +1-540-231-1503
}

\begin{abstract}
Commercial motor vehicle safety is of utmost importance, as crashes involving commercial motor vehicles often result in significant property damage, injuries, fatalities, and financial loss for fleets. However, fleet managers are often unsure what strategies other fleets have used to successfully improve safety. To identify best practices, researchers completed case studies with nine commercial motor vehicle fleets that successfully improved their safety performance. A content analysis was performed, and the successful strategies were organized into the Haddon Matrix. Results showed that there was no one single strategy that fleets used to improve safety. Instead, fleets relied on a comprehensive approach focusing on pre-crash countermeasures, including addressing hiring practices, driver training, fleet safety culture, safety technologies, scheduling, and maintenance. However, an enhanced safety culture and advanced safety technology were identified as critical components to their safety improvement. Results from this study may help fleets understand what their peers have used to successfully improve safety and which strategies may not be as helpful.
\end{abstract}

Keywords: truck; advanced driver assistance system; safety culture; crash

check for

updates

Citation: Camden, M.C.; Hickman, J.S.; Hanowski, R.J. Reversing Poor Safety Records: Identifying Best Practices to Improve Fleet Safety. Safety 2022, 8, 2. https://doi.org/ $10.3390 /$ safety 8010002

Academic Editor: Garrett Mattos

Received: 20 November 2021

Accepted: 21 December 2021

Published: 24 December 2021

Publisher's Note: MDPI stays neutral with regard to jurisdictional claims in published maps and institutional affiliations.

Copyright: (C) 2021 by the authors. Licensee MDPI, Basel, Switzerland. This article is an open access article distributed under the terms and conditions of the Creative Commons Attribution (CC BY) license (https:// creativecommons.org/licenses/by/ $4.0 /)$.

\section{Introduction}

Each year, thousands of commercial motor vehicle (CMV) fleets struggle to improve their safety records. Over the previous five years, the Federal Motor Carrier Safety Administration (FMCSA) added an average of 2783 fleets to the high-risk list [1]. These fleets had two or more scores in FMCSA's Safety Management System at or above the 90th percentile for at least one month and had not received an on-site investigation within the previous 12 months (or 18 months if not a passenger carrier). Additionally, insurance companies may target fleets for safety improvement interventions. Often these interventions include an initial warning letter to notify the fleet of high crash rates (in comparison to other fleets), in-person safety audits, the creation or revision of a comprehensive plan to improve safety, and/or shutting down the fleet's operations. A fleet's safety improvement plan will address how the fleet will develop new systems or revise existing systems to reduce crash risk, and may include examining hiring criteria, revised drug and alcohol testing, scheduling and dispatching practices, vehicle maintenance, equipment purchases, safety technologies, discipline procedures, incentive and reward programs, anonymous risk reporting systems, and driver training and education. With so many options available, some fleets may have trouble knowing which strategies to implement, and they could benefit from knowing how other fleets have successfully improved safety.

There has been extensive research investigating the effectiveness of safety-improvement strategies. These can generally be grouped into the following six categories: (1) hiring policies and practices, (2) training policies and practices, (3) programs to improve safety culture, (4) driver dispatching and scheduling, (5) safety technologies, and (6) vehicle maintenance practices [2]. A summary of existing CMV research in these categories is presented below. 


\subsection{Driver Recruitment, Hiring, and Compensation}

One of the logical ways for fleets to achieve lower crash rates is to hire safe drivers. To find the safest drivers, carriers should closely examine an applicant's driving record for recent violations or involvement in crashes [2,3]. Additionally, fleets should weigh drivers' previous experience, training, and past employer recommendations before making a hiring decision [3]. Finally, some research suggests that carriers should hire drivers with at least 2 years of driving experience during which no more than six total points accrued on the applicants' motor vehicle record, including no more than one recent crash or three moving violations [4]. Finally, research suggests that increasing driver compensation, providing health insurance, and/or compensating drivers for all hours worked are associated with significant safety improvements [5-7].

\subsection{Driver Training}

In addition to prioritizing hiring the safest drivers possible, driver education and training are critical components of a fleet's overall safety program. New hire safety education and training should include an introduction to the fleet's safety policies, technologies, hours of service (HOS) regulations, defensive driving, vehicle inspections, and behind-thewheel training or mentoring $[3,4,8]$. Research also suggests that recurring education and training for all drivers is important, to maintain safety $[4,9,10]$. This education and training may occur during periodic safety meetings, via daily/weekly/monthly safety messaging, and/or via online instruction.

\subsection{Safety Culture}

Research across many industries has shown that many common safety culture indicators, such as company leadership support and commitment to safety [11], frequency and quality of safety communication [12], management's perception of risk [13], workplace demands [11], job satisfaction [13], and involvement in safety-related decision making [14], are associated with workplace injuries and fatalities. Specifically related to fleets, previous research shows that safety culture is associated with driver safety performance [3,15]. Fleets with positive safety cultures often value driver safety, invest in proven safety technologies and programs, hire the safest drivers, create programs to reward and retain safe drivers, develop a safety reporting system, value and encourage driver health and wellness, and create self-accountability for safety $[14,16]$. Research has shown that fleets with strong safety cultures have significant commitment and dedication to safety from their executive team $[4,15,17]$. Additionally, research has shown that incentive/reward programs are effective at improving driver safety $[3,10]$. Finally, recent research has shown the importance between driver health and wellness and safety [18], and fleets that value programs to improve driver health and wellness may experience reduced crashes.

\subsection{Driver Dispatching and Scheduling}

Driver fatigue is a major contributor to CMV crash risk [19-21]. Heitmann et al. found that a risk-informed performance-based scheduling program reduced driver fatigue risk by approximately $25 \%$ and reduced crash rates by $23.5 \%$ [22]. In addition to developing schedules to reduce the risk of fatigue, Knipling and Bergoffen suggested that fleets create contracts to discourage long detention times, develop routes to maximize travel on interstate roadways, limit travel time during known instances of high traffic congestion, limit routes through existing construction zones, maximize daytime driving, and promote the use of breaks to reduce fatigue [23]. Finally, Hickman et al. showed that the use of electronic logging devices (ELD) was associated with fewer crashes and HOS violations [24].

\subsection{Safety Technologies}

A wide range of safety technologies is available for fleets. Some of these technologies provide safety-related alerts to drivers, while more advanced systems actually brake or steer the vehicle during a safety-related event. Although there is much research examining the 
effectiveness of safety technologies in light vehicles, there is little peer-reviewed research to document the effectiveness of safety technologies in CMVs. However, the research that does focus on CMVs shows that advanced safety technologies do significantly improve safety [25-31]. Further research also shows some of these technologies have a positive return on investment with quick payback periods [25,32].

\subsection{Vehicle Maintenance}

Vehicle maintenance is a major focus of CMV roadside inspections. Roadside inspections are designed to identify trucks with poorly maintained safety components (i.e., brakes). Research has shown that preventative maintenance helps keep CMVs in proper working order [2,15]. Additionally, Corsi and Barnard identified best practices that fleets can use to improve vehicle safety, including the use of maintenance software to automatically track and schedule preventative maintenance, outsourcing maintenance when appropriate, and frequent vehicle inspections [3].

\subsection{Study Objective}

Although there is existing research documenting individual strategies that fleets may use to improve safety, there is a lack of recent research documenting comprehensive programs that fleets have used to successfully improve safety during normal operations. Thus, the goal of this study was to conduct comprehensive case studies of nine heavy vehicle fleets that achieved an improvement in their safety performance to identify the following:

1. Safety strategies that were used to significantly improve safety performance;

2. Safety strategies that did not improve safety performance;

3. Barriers to implementing safety programs and strategies to overcome these barriers.

\section{Materials and Methods}

This section describes the participants, case study methodology, and analysis.

\subsection{Participants}

Nine CMV fleets participated in this study. To be eligible to participate, CMV fleets must have significantly reduced their crashes, violations, claims, and/or scores in the FMCSA's Compliance, Safety, and Accountability (CSA) system. Researchers identified 14 potentially eligible CMV fleets with the assistance of CMV insurance companies or via state trucking associations. Once an eligible fleet was identified, researchers examined that fleet's crash, violation, and/or CSA scores to confirm safety improvement within the previous 10 years. These data were obtained from the FMCSA CSA system; no additional objective safety data (i.e., crash reports or carrier data sets) were obtained by the researchers to verify the safety improvements.

Table 1 provides demographic information for the nine fleets that were identified. There was a wide range in the sizes of the fleets that participated in the case studies, ranging from a fleet with fewer than 50 power units to a fleet with more than 1000 power units.

Table 1. Fleet demographics.

\begin{tabular}{ccc}
\hline Fleet & No. of Power Units & Operation \\
\hline A & $>1000$ & For-hire, Truckload \\
B & $501-1000$ & For-hire, Truckload \\
C & $501-1000$ & For-hire, Truckload \\
D & $101-500$ & For-hire, Truckload \\
E & $101-500$ & For-hire, Truckload \\
F & $51-100$ & For-hire, Truckload \\
G & $51-100$ & For-hire, Truckload \\
H & $101-500$ & For-hire, Truckload \\
I & $<50$ & For-hire, Less than Truckload \\
\hline
\end{tabular}




\subsection{Fleet Case Studies}

Researchers conducted in-depth interviews for each of the nine CMV fleets. At least two individuals were interviewed for each fleet, and at least one of the interviewees was an individual responsible for fleet safety (i.e., a safety director, VP of Safety, safety manager, human resource manager, etc.). The second interviewee may have been a driver, fleet executive, a second safety manager, trainer, or human resource manager. Researchers structured these interviews based on the Haddon Matrix [33,34] and focused on factors associated with the fleet's culture, drivers, managers, and vehicles. The interviews were semi-structured and focused on the following seven topics:

1. Events that precipitated the efforts to improve safety;

2. Details related to which safety initiatives were implemented, with a focus on strategies related to hiring, training, technologies, culture, maintenance, and scheduling;

3. The timeline for implementing the safety initiatives;

4. Details about why the specific safety initiatives were selected and how they were developed;

5. Information about how the safety initiatives were implemented;

6. Pre- and post-crash rates and the violations and CSA scores pre- and post-safety initiative implementation;

7. The measures used to assess the success of the safety initiatives;

8. The fleet's perceived effectiveness of the safety initiatives.

\subsection{Content Analysis}

The content analysis methodology was based on the framework analysis [35]. Each of the interviews was recorded and coded to identify all relevant information, including all themes and subthemes. Finally, common themes, subthemes, and specific strategies were indexed and placed in the Haddon Matrix.

\section{Results}

Table 2 shows the substantial safety improvement in each of the participating carriers along with the strategies the fleet believed had the largest impact on their improved safety performance. Non-substantial improvements are not included (a one percentile improvement, no change, insufficient data to analyze, etc.).

Table 2. Substantial fleet safety improvement results.

\begin{tabular}{|c|c|c|}
\hline Fleet & Safety Performance Improvement & Most Impactful Safety Strategies \\
\hline A & $\begin{array}{l}\text { 1. FMCSA-reportable crash rate: } 19.5 \% \text { reduction } \\
\text { 2. CSA Crash Indicator: } 20 \text {-percentile improvement } \\
\text { 3. Fleet-reported preventable rear-end crashes: } 56 \% \text { reduction }\end{array}$ & $\begin{array}{l}\text { 1. Comprehensive training } \\
\text { 2. Automatic emergency braking (AEB) }\end{array}$ \\
\hline B & $\begin{array}{l}\text { 1. FMCSA-reportable crash rate: } 31.7 \% \text { reduction } \\
\text { 2. CSA Crash Indicator: } 70 \text {-percentile improvement } \\
\text { 3. CSA Unsafe Driving: } 49 \text {-percentile improvement }\end{array}$ & $\begin{array}{l}\text { 1. Comprehensive suite of safety technologies including } \\
\text { video-based driver monitoring systems (VDMS), lane } \\
\text { departure warning (LDW), and AEB } \\
\text { 2. Hiring criteria focused on safety performance }\end{array}$ \\
\hline $\mathrm{C}$ & $\begin{array}{l}\text { 1. Fleet-reported preventable crashes: } 75.6 \% \text { reduction } \\
\text { 2. CSA Unsafe Driving: } 17 \text {-percentile improvement }\end{array}$ & 1. Enhanced safety culture \\
\hline $\mathrm{D}$ & $\begin{array}{l}\text { 1. CSA Unsafe Driving: } 45 \text {-percentile improvement } \\
\text { 2. CSA Maintenance: } 24 \text {-percentile improvement } \\
\text { 3. CSA HOS: } 70 \text {-percentile improvement } \\
\text { 4. Fleet-reported preventable, rear-end crashes: } 100 \% \text { reduction } \\
\text { 5. Fleet-reported preventable rollovers: } 100 \% \text { reduction }\end{array}$ & $\begin{array}{l}\text { 1. Enhanced safety culture } \\
\text { 2. Safety technology suite of VDMS, LDW, and AEB }\end{array}$ \\
\hline E & 1. FMCSA-reportable crashes: $35.8 \%$ reduction & $\begin{array}{l}\text { 1. Enhanced safety culture } \\
\text { 2. Safety technologies including AEB, LDW, and VDMS }\end{array}$ \\
\hline $\mathrm{F}$ & $\begin{array}{l}\text { 1. FMCSA-reportable crash rate: } 66.3 \% \text { reduction } \\
\text { 2. CSA Crash Indicator: } 44 \text {-percentile improvement }\end{array}$ & $\begin{array}{l}\text { 1. Enhanced safety culture } \\
\text { 2. Safety-focused hiring criteria }\end{array}$ \\
\hline
\end{tabular}


Table 2. Cont.

\begin{tabular}{cll}
\hline Fleet & \multicolumn{1}{c}{ Safety Performance Improvement } & \multicolumn{1}{c}{ Most Impactful Safety Strategies } \\
\hline G & $\begin{array}{l}\text { 1. FMCSA-reportable crash rate: } 66.3 \% \text { reduction } \\
\text { 2. CSA Crash Indicator: 38-percentile improvement }\end{array}$ & 1. Safety technologies including VDMS, AEB, and ELD \\
\hline H & $\begin{array}{l}\text { 1. FMCSA-reportable crash rate: } 24.4 \% \text { reduction } \\
\text { 2. CSA Crash Indicator: 39.7-percentile improvement }\end{array}$ & $\begin{array}{l}\text { 1. Safety-focused hiring criteria } \\
\text { 2. Enhanced safety culture }\end{array}$ \\
\hline & $\begin{array}{l}\text { 1. Fleet-reported overall incidents: } 53.6 \% \text { reduction } \\
\text { I }\end{array}$ & $\begin{array}{l}\text { 2. FMCSA-reportable crashes: } 100 \% \\
\text { 1. Enhanced safety culture } \\
\text { 3. CSA HOS: } 46-\text { percentile improvement }\end{array}$ \\
\hline
\end{tabular}

\subsection{Fleet A Results}

Fleet A had a history of focusing on safety, and as a part of this focus, regularly conducted internal safety assessments and industry benchmarking studies. As a result of these analyses, Fleet A decided additional strategies were needed to reduce crashes. Specifically, Fleet A identified a need to improve training for new and existing drivers. Previously, driver training was implemented consistently across each of the fleet's locations. This created inconsistent expectations and differing knowledge and skills of drivers across the fleet. Additionally, an internal safety assessment identified an opportunity to reduce rear-end crashes and at-fault, preventable crashes. These results lead the fleet to investigate the use of safety technologies as a crash reduction countermeasure. Fleet A used the strategies shown in Table 3 to improve its safety performance.

Table 3. Fleet A's safety improvement strategies.

\begin{tabular}{|c|c|}
\hline Type of Strategy & Strategy Details \\
\hline Driver hiring & $\begin{array}{l}\text { 1. Pre-employment Screening Program (PSP). } \\
\text { 2. Required minimum of } 1 \text { year of driving experience. } \\
\text { 3. Allowed a maximum of three moving violations in the previous } 3 \text { years, with a maximum of one reckless } \\
\text { driving or excessive speeding (over } 15 \mathrm{mph} \text { ) violation. }\end{array}$ \\
\hline Driver training & $\begin{array}{l}\text { 1. Analyzed current crash contributing factors to identify skills that drivers may lack. } \\
\text { 2. Created a completely new comprehensive driver training program. } \\
\text { 3. Had frequent discussions between management and drivers about the program. } \\
\text { 4. Conducted 2-h new driver training. } \\
\text { 5. Conducted periodic refresher training for all fleet drivers to address common crash types and contributing factors. } \\
\text { 6. Hired full-time, experienced peer driver trainers to implement the program at all terminals. }\end{array}$ \\
\hline Safety culture & $\begin{array}{l}\text { 1. Full-time trainers provided a "face" to the fleet's safety culture. } \\
\text { 2. Implemented open door policies related to safety. } \\
\text { 3. Implemented safety reward program with non-monetary rewards. } \\
\text { 4. Safety bonuses were pilot tested and were found not to be effective at improving safety. }\end{array}$ \\
\hline $\begin{array}{l}\text { Dispatching and } \\
\text { scheduling }\end{array}$ & 1. Scheduled routes based on an average $45 \mathrm{mph}$ for long-haul deliveries. \\
\hline $\begin{array}{c}\text { Safety } \\
\text { technologies }\end{array}$ & $\begin{array}{l}\text { 1. Began purchasing AEB on trucks in 2012. Pilot testing showed a positive return on investment. By 2018, all } \\
\text { trucks were equipped with AEB. } \\
\text { 2. All trucks purchased included LDW, blind spot warning, and VDMS. }\end{array}$ \\
\hline $\begin{array}{c}\text { Vehicle } \\
\text { maintenance }\end{array}$ & tegies. \\
\hline
\end{tabular}

\subsection{Fleet B Results}

In 2012, Fleet B's Vice President of Safety retired. That individual's replacement was not successful at maintaining the fleet's strong safety culture. As a result, the fleet's crash statistics and CSA scores worsened, with some CSA scores climbing above the 90th percentile. To address the safety issue, a new Vice President of Safety was hired, and the strategies in Table 4 were implemented to improve the fleet's safety performance. 
Specifically, Fleet B decided to equip all new trucks with the newest factory-installed safety technologies. This was decided in an effort to reduce the number of preventable crashes.

Table 4. Fleet B's safety improvement strategies.

\begin{tabular}{|c|c|}
\hline Type of Strategy & Strategy Details \\
\hline Driver hiring & $\begin{array}{l}\text { 1. Strictly adhered to hiring criteria without exceptions (this had been done in the past). } \\
\text { 2. Used FMCSA's PSP. } \\
\text { 3. Required zero reportable crashes in the past } 3 \text { years, zero serious moving violations, and zero } \\
\text { failed drug tests or convictions for driving under the influence. } \\
\text { 4. Required stable employment history. } \\
\text { 5. Started hair testing in } 2018 \text {. }\end{array}$ \\
\hline Driver training & $\begin{array}{l}\text { 1. Paired all newly licensed drivers with a mentor who was an experienced driver for } 1 \text { month. } \\
\text { 2. Implemented an improved behind-the-wheel test that all inexperienced drivers had to pass before } \\
\text { driving on their own. } \\
\text { 3. Provided all drivers regular driver coaching based on VDMS data. }\end{array}$ \\
\hline Safety culture & $\begin{array}{l}\text { 1. Replaced Vice President of Safety in } 2018 . \\
\text { 2. Sent regular safety communications from the executive team. } \\
\text { 3. Required drivers to sign a safety pledge. } \\
\text { 4. Made safety a top priority. } \\
\text { 5. Implemented driver safety scorecards with monetary rewards for goal achievement. } \\
\text { 6. Provided positive driver coaching. }\end{array}$ \\
\hline $\begin{array}{l}\text { Dispatching and } \\
\text { scheduling }\end{array}$ & $\begin{array}{l}\text { 1. Dispatchers were instructed to never push HOS limits. Violations to this policy were to result in } \\
\text { immediate termination. }\end{array}$ \\
\hline Safety technologies & $\begin{array}{l}\text { 1. All trucks were equipped with AEB, LDW, adaptive cruise control, and all trailers were equipped } \\
\text { with roll stability control. } \\
\text { 2. All trucks were equipped with VDMS. }\end{array}$ \\
\hline Vehicle maintenance & 1. Updated pre-trip inspection lists based on flatbed and reefer trailers and for specific types of loads. \\
\hline
\end{tabular}

\subsection{Fleet $C$ Results}

Fleet $C$ routinely performed internal safety audits and benchmarked its safety statistics against other peer fleets. In 2011, these internal safety audits showed unacceptable increases in crashes, specifically preventable crashes, and CSA scores. As a result, the fleet hired a new Director of Safety. This individual assessed the current safety policies and programs and revised or replaced many aspects of the fleet's operating procedure. The new Director of Safety implemented the strategies in Table 5 to successfully improve safety.

Table 5. Fleet C's safety improvement strategies.

\begin{tabular}{|c|c|}
\hline Type of Strategy & Strategy Details \\
\hline Driver hiring & $\begin{array}{l}\text { 1. Implemented new, strict hiring policy. } \\
\text { 2. Required drivers to have a maximum of two speeding violations in the past year (maximum of one serious } \\
\text { speeding violation ever); zero preventable rear-end crashes in the past year; zero preventable bridge strikes in } \\
\text { the past year, zero preventable sideswipes, jackknifes, rollovers, or run-off-road crashes in the past } 2 \text { years; } \\
\text { maximum of four preventable crashes in the past } 3 \text { years; and at least } 1 \text { year of driving after the last } \\
\text { preventable crash. }\end{array}$ \\
\hline raining & $\begin{array}{l}\text { 1. Created a driver finishing school in } 2012 \text {. This paired newly licensed drivers with an experienced driver for } \\
1 \text { month and incorporated additional in-class learning and an extended road test. } \\
\text { 2. Required all drivers to attend biannual safety meetings. }\end{array}$ \\
\hline Safety culture & $\begin{array}{l}\text { 1. Replaced Director of Safety in } 2011 . \\
\text { 2. Created family events for drivers' families. } \\
\text { 3. Sent biweekly safety communications from managers and shared overall fleet safety statistics and CSA scores. } \\
\text { 4. Held management meetings to discuss and compare terminal safety data and develop strategies for improvement. } \\
\text { 5. Implemented safety bonus program. } \\
\text { 6. Held quarterly meetings with top executives to review safety statistics. }\end{array}$ \\
\hline
\end{tabular}


Table 5. Cont.

\begin{tabular}{cl}
\hline Type of Strategy & \multicolumn{1}{c}{ Strategy Details } \\
\hline $\begin{array}{c}\text { Dispatching and } \\
\text { scheduling }\end{array}$ & 1. Reduced the number of drivers each manger oversaw from 50 to 35. \\
\hline $\begin{array}{c}\text { Safety } \\
\text { technologies }\end{array}$ & $\begin{array}{l}\text { 1. In 2012, all trucks were equipped with telematics to track speeding. } \\
\text { 2. In 2015, all new trucks were equipped with AEB. }\end{array}$ \\
\hline $\begin{array}{c}\text { Vehicle } \\
\text { maintenance }\end{array}$ & 1. No new strategies. \\
\hline
\end{tabular}

\subsection{Fleet D Results}

In 2012, Fleet D received a warning from their insurance provider of an unacceptably high number of HOS violations. These resulted in CSA HOS scores above the 90th percentile. In response, Fleet D replaced its Director of Safety and immediately implemented ELDs in all trucks. Additionally, the new Director of Safety used numerous other safety programs and policies (Table 6) to improve safety performance, including eliminating preventable rear-end and rollover crashes identified in each of the previous 3 years.

Table 6. Fleet D's safety improvement strategies.

\begin{tabular}{|c|c|}
\hline Type of Strategy & Strategy Details \\
\hline Driver hiring & $\begin{array}{l}\text { 1. Participated in FMCSA's PSP. } \\
\text { 2. Maintained hiring criteria including at least } 1 \text { year of driving experience, drivers at least } 23 \text { years old, } \\
\text { and a maximum of two moving violations in the past year and no more than three in the past } 3 \text { years. }\end{array}$ \\
\hline Driver training & $\begin{array}{l}\text { 1. Required all new hires to take safety training that covered general defensive driving practices and } \\
\text { provided an introduction to the fleet's overall safety performance. } \\
\text { 2. Held monthly refresher training for all drivers to address recent issues or seasonal driving tips. } \\
\text { 3. Provided additional supplemental training to individual drivers on an as-needed basis. } \\
\text { 4. Provided one-on-one coaching based on VDMS data. }\end{array}$ \\
\hline Safety culture & $\begin{array}{l}\text { 1. Hired a new Director of Safety. } \\
\text { 2. Created top-management buy-in on safety-related issues and conducted weekly safety meetings with } \\
\text { the executive team to review safety statistics, violations, and HOS compliance. } \\
\text { 3. Held management training on HOS regulations. } \\
\text { 4. Sent an instant alert to all managers if a driver failed a Department of Transportation (DOT) inspection. } \\
\text { 5. Gave quarterly safety bonuses based on violations, crashes, and inspections. } \\
\text { 6. Implemented a driver of the year recognition program. } \\
\text { 7. Implemented 24-h/7-day-a-week ability to reach a fleet manager immediately without needing to } \\
\text { leave a message. } \\
\text { 8. Implemented a program to identify driver distress and provide an immediate follow-up for a wellness } \\
\text { check by the Director of Safety. }\end{array}$ \\
\hline $\begin{array}{l}\text { Dispatching and } \\
\text { scheduling }\end{array}$ & $\begin{array}{l}\text { 1. Implemented ELDs in } 2012 \text {. } \\
\text { 2. Implemented new scheduling software to gain better visibility into drivers' real-time duty status and } \\
\text { remaining hours. }\end{array}$ \\
\hline Safety technologies & $\begin{array}{l}\text { 1. Installed speed limiters. } \\
\text { 2. Starting in 2015, equipped all new trucks with AEB, LDW, VDMS, and roll stability control. To date, } \\
50 \% \text { of the fleet is equipped with the technologies. }\end{array}$ \\
\hline Vehicle maintenance & $\begin{array}{l}\text { 1. Transitioned to a 3-year fleet replacement cycle on all power units. } \\
\text { 2. Had mechanics perform a detailed inspection when the truck returned after each trip. } \\
\text { 3. Implemented a preventative maintenance program to repair and replace parts prior to an issue. } \\
\text { 4. Implemented air disc brakes. }\end{array}$ \\
\hline
\end{tabular}

\subsection{Fleet E Results}

Similarly to some of the other fleets that participated in this case study, Fleet E was historically a safety conscious fleet that regularly assessed the effectiveness of its current 
safety programs. These regular assessments led to periodic adjustments to its safety policies and practices. These helped the fleet experience a significant gradual improvement in serious crashes, with an additional 10\% crash reduction in the previous 8 months that coincided with the implementation of the latest generation of collision mitigation technologies and with enhanced screening of new hires. Fleet E's safety improvement strategies are shown in Table 7.

Table 7. Fleet E's safety improvement strategies.

\begin{tabular}{|c|c|}
\hline Type of Strategy & Strategy Details \\
\hline Driver hiring & $\begin{array}{l}\text { 1. Began using a personality assessment in the driver selection process to identify individuals that } \\
\text { may be a good fit as a driver. } \\
\text { 2. Used strong hiring criteria, including a minimum age of } 23 \text { years old, already possessing a } \\
\text { commercial driver's license, maximum of three moving violations in the past } 3 \text { years; zero } \\
\text { preventable reportable crashes in the last year, zero major moving violations in the past } 5 \text { years } \\
\text { (maximum of one ever), and a maximum of three different jobs in the last year. } \\
\text { 3. Required passing DOT physical using the fleet's in-house physician. } \\
\text { 4. Administered a physical capacity test during the DOT physical. } \\
\text { 5. Implemented hair testing for drugs and alcohol with a 90-day detection window. }\end{array}$ \\
\hline Driver training & $\begin{array}{l}\text { 1. Teamed all new inexperienced drivers with an experienced driver for behind-the-wheel training. } \\
\text { 2. Provided a 3-day new driver orientation that involved an introduction to the fleet's safety culture, } \\
\text { a review of standard safety skills, an introduction to the safety technologies, presentations from top } \\
\text { management, and a skills test. } \\
\text { 3. Held quarterly refresher training with an in-house driving simulator. } \\
\text { 4. Provided remedial training on a driving simulator following all crashes or near crashes. }\end{array}$ \\
\hline Safety culture & $\begin{array}{l}\text { 1. Demonstrated top management support for safety to all drivers during new driver orientation. } \\
\text { 2. Emphasized that safety is valued over all else. } \\
\text { 3. Demonstrated importance of driver safety through investments in safety technologies. } \\
\text { 4. Required sleep apnea testing at hire (paid for by the fleet), including a CPAP machine if needed } \\
\text { (paid for by the fleet with a 1-year commitment from the driver). } \\
\text { 5. Issued driver safety scorecards based on inspections and crash-free miles. }\end{array}$ \\
\hline $\begin{array}{l}\text { Dispatching and } \\
\text { scheduling }\end{array}$ & $\begin{array}{l}\text { 1. Rescheduled all loads upon request when drivers felt unsafe or were running out of driving or } \\
\text { on-duty hours. }\end{array}$ \\
\hline Safety technologies & $\begin{array}{l}\text { 1. Equipped trucks with VDMS, speed limiters, AEB, and adaptive cruise control beginning in } 2016 . \\
\text { 2. Beginning in 2019, all new truck purchases were equipped with the most advanced AEB, adaptive } \\
\text { cruise control, LDW, and blind spot warning systems. }\end{array}$ \\
\hline Vehicle maintenance & 1. Had a dedicated technician inspect every power unit and trailer upon return to the fleet's terminal. \\
\hline
\end{tabular}

\subsection{Fleet F Results}

Fleet F historically had low crash rates and good CSA scores. However, in 2017, the fleet identified several opportunities to become even safer, including the implementation of safety technologies designed to reduce preventable crashes. As a result of the strategies in Table 8, Fleet F reduced its FMCSA-reportable crash rate from an average of 0.86 crashes per million miles to 0.29 crashes per million miles.

Table 8. Fleet F safety improvement strategies.

Type of Strategy

Driver hiring

\section{Strategy Details}

1. Enforced strict hiring criteria, including a minimum age requirement of 23 years old with at least

3 years of experience.

2. Enforced a policy of zero crashes in the past 5 years, and no violation in the past year.

3. Gave hourly pay instead of pay-per-mile. 
Table 8. Cont.

\begin{tabular}{|c|c|}
\hline Type of Strategy & Strategy Details \\
\hline Driver training & $\begin{array}{l}\text { 1. Upon hire, each driver met with the Safety Director to review the safety policies, HOS regulations, } \\
\text { and ELD functionality. } \\
\text { 2. Teamed new hires with an experienced driver for at least the first two weeks. } \\
\text { 3. Held quarterly refresher training for all drivers, focusing on seasonal, geographic, or important } \\
\text { safety-related updates. } \\
\text { 4. Sent periodic safety-related tips and messages via the dispatching device. } \\
\text { 5. Provided individual coaching based on VDMS data. }\end{array}$ \\
\hline Safety culture & $\begin{array}{l}\text { 1. Created a family environment where all drivers know each other by name and all administrative } \\
\text { personnel know each driver by name. } \\
\text { 2. Safety director developed a personal rapport with drivers. } \\
\text { 3. Addressed driver feedback and concerns as soon as possible. } \\
\text { 4. Conducted safety director ride-alongs with drivers to understand their perspectives. } \\
\text { 5. Offered safety bonus program based on incident-free miles. } \\
\text { 6. Used a peer observation and anonymous safety reporting system. } \\
\text { 7. Had an open-door policy to discuss all feedback, comments, and/or concerns related to safety. }\end{array}$ \\
\hline $\begin{array}{l}\text { Dispatching and } \\
\text { scheduling }\end{array}$ & $\begin{array}{l}\text { 1. Equipped all trucks with ELDs in } 2017 . \\
\text { 2. Strictly enforced HOS regulations. } \\
\text { 3. Scheduled drivers based on their route/schedule preferences as much as possible. }\end{array}$ \\
\hline Safety technologies & $\begin{array}{l}\text { 1. In 2017, equipped all trucks with VDMS. } \\
\text { 2. In 2018, equipped all new trucks with AEB and LDW. }\end{array}$ \\
\hline Vehicle maintenance & $\begin{array}{l}\text { 1. Supported in-house } 24 \text {-h-a-day maintenance shop. } \\
\text { 2. Followed a preventative maintenance schedule with all trucks serviced every } 7500-10,000 \text { miles } \\
\text { and all trailer tires and brakes serviced every } 30 \text { days. }\end{array}$ \\
\hline & $\begin{array}{l}\text { 3.7. Fleet G Results } \\
\text { In 2012, Fleet G's ownership changed. Although the change in ownership was not } \\
\text { specifically related to safety, Fleet G's safety performance was a factor in the decision. } \\
\text { Under the new leadership, Fleet G decided to examine and revamp several safety-related } \\
\text { policies and procedures, including the purchase of all new vehicles and investing in VDMS } \\
\text { in 2017. This was implemented as a way to address high vehicle out-of-service rates and } \\
\text { instances of risky driving. As a result, between } 2017 \text { and } 2018 \text {, Fleet G doubled the number } \\
\text { of power units and was able to reduce its FMCSA-reportable crash rate from } 1.04 \text { crashes } \\
\text { per million miles to } 0.35 \text { crashes per million miles. Overall, Fleet G implemented the safety } \\
\text { improvement strategies shown in Table } 9 \text {. }\end{array}$ \\
\hline Type of Strategy & Strategy Details \\
\hline Driver hiring & $\begin{array}{l}\text { 1. Participated in FMCSA's PSP. } \\
\text { 2. Used hiring criteria that included at least } 2 \text { years of driving experience, no more than } 5.5 \text { points on } \\
\text { the driver's motor vehicle record, and no reckless driving violations. } \\
\text { 3. Preferred hiring drivers with experience transporting live agricultural animals. } \\
\text { 4. Safety Director personally checked references from previous employers. } \\
\text { 5. Required applicants to perform an agility test to identify mobility challenges. Identified } \\
\text { accommodations and job placement based on results from the agility test. }\end{array}$ \\
\hline Driver training & $\begin{array}{l}\text { 1. Provided 3-day new driver safety training to review fleet-specific safety policies and regulations } \\
\text { and an overview of federal and state regulations related to transporting live animals. } \\
\text { 2. Paired new drivers without live-haul experience with an experienced driver for approximately } 1 \\
\text { month to gain confidence with the unique challenges associated with live hauls. } \\
\text { 3. Held semi-annual, in-person refresher training to review seasonal issues. } \\
\text { 4. Provided monthly web-based education on safe driving strategies. } \\
\text { 5. Provided individual coaching based on VDMS data. }\end{array}$ \\
\hline
\end{tabular}


Table 9. Cont.

\begin{tabular}{|c|c|}
\hline Type of Strategy & Strategy Details \\
\hline Safety culture & $\begin{array}{l}\text { 1. Instituted new safety-focused leadership. } \\
\text { 2. Created a family environment with all drivers, management, dispatchers, and administrative } \\
\text { personnel. } \\
\text { 3. Held fleet-sponsored events with drivers and their families. }\end{array}$ \\
\hline $\begin{array}{l}\text { Dispatching and } \\
\text { scheduling }\end{array}$ & $\begin{array}{l}\text { 1. Implemented ELDs in } 2012 . \\
\text { 2. Used GPS tracking to identify where drivers were at all times and allowed dispatchers to } \\
\text { estimated remaining available hours. }\end{array}$ \\
\hline Safety technologies & $\begin{array}{l}\text { 1. In 2017, equipped all trucks with a VDMS. } \\
\text { 2. In 2018, equipped all new trucks with AEB. No trucks equipped with AEB have experienced a } \\
\text { rear-end crash to date. } \\
\text { 3. All trucks equipped with speed limiters. }\end{array}$ \\
\hline Vehicle maintenance & $\begin{array}{l}\text { 1. Operated an in-house maintenance facility. } \\
\text { 2. Replaced parts if a driver reported an issue instead of waiting for the parts to exceed regulation. }\end{array}$ \\
\hline
\end{tabular}

\subsection{Fleet H Results}

Over time, Fleet $\mathrm{H}$ experienced an upward trend of crash involvement, until its CSA Crash Indicator score was above the 90th percentile. As a result, a new Safety Director was hired to identify areas for improvement and to reduce the fleet's crash rate. Fleet $\mathrm{H}$ used the strategies shown in Table 10 to gradually reduce its reportable crash rates from 0.78 crashes per million miles to 0.59 crashes per million miles and reduce its CSA Crash Indicator score below the high-risk threshold.

Table 10. Fleet H's safety improvement strategies.

\begin{tabular}{|c|c|}
\hline Type of Strategy & Strategy Details \\
\hline Driver hiring & $\begin{array}{l}\text { 1. Participated in FMCSA's PSP. } \\
\text { 2. Used hiring criteria that included a minimum of } 1 \text { year of experience (exceptions made if a driver } \\
\text { performed well on the road test), no preventable crashes, a maximum of five points on the driver's } \\
\text { motor vehicle record in the past } 5 \text { years, and must have good referrals from previous employers. } \\
\text { 3. Detailed road test prior to employment offer } \\
\text { 4. Applicants had personal, in-person interviews with the Safety Director. }\end{array}$ \\
\hline Driver training & $\begin{array}{l}\text { 1. Held one-day, on-the-job training for all new drivers. This training teamed new drivers with } \\
\text { experienced drivers. } \\
\text { 2. Partnered drivers with less than } 1 \text { year of experience with an experienced driver for } 1 \text { month to } \\
\text { gain experience. } \\
\text { 3. Held quarterly safety training to review recent crash data and crash costs. } \\
\text { 4. Provided monthly web-based training modules to review key safety skills. }\end{array}$ \\
\hline Safety culture & $\begin{array}{l}\text { 1. Hired a new Safety Director. } \\
\text { 2. Created a family environment where all drivers are known by name by everyone in administrative, } \\
\text { dispatch, and management roles. } \\
\text { 3. Actively listened to driver feedback about risky situations and needs. } \\
\text { 4. Offered a yearly profit share bonus to create ownership and accountability. }\end{array}$ \\
\hline $\begin{array}{l}\text { Dispatching and } \\
\text { scheduling }\end{array}$ & $\begin{array}{l}\text { 1. Scheduled routes to match, as closely as possible, driver preferences for hours, time at home, and } \\
\text { haul length. } \\
\text { 2. Opened a new regional terminal to prioritize home time every few days for all drivers. } \\
\text { 3. Provided all dispatchers with HOS training. } \\
\text { 4. Required dispatchers to complete the same monthly web-based training as drivers. }\end{array}$ \\
\hline Safety technologies & 1. No advanced safety technologies. However, the fleet is currently evaluating VDMS. \\
\hline Vehicle maintenance & 1. No new strategies. \\
\hline
\end{tabular}




\subsection{Fleet I Results}

Fleet I was the smallest fleet to participate in the study. Due to its size, historically the fleet did not have many reportable crashes; however, it had experienced a gradual increase in less severe incidents. Additionally, the fleet experienced a rise in HOS violations. To help address these two safety issues, Fleet I hired a new Safety Manager, who implemented the strategies shown in Table 11. These strategies helped Fleet I reduce the number of less severe incidents from 28 to 13 in 2017-2018, improved its CSA HOS score, and eliminated FMCSA-reportable crashes in 2018.

Table 11. Fleet I's safety improvement strategies.

\begin{tabular}{|c|c|}
\hline Type of Strategy & Strategy Details \\
\hline Driver hiring & $\begin{array}{l}\text { 1. Required a minimum of } 3 \text { years' experience. } \\
\text { 2. Offered a driver referral bonus. }\end{array}$ \\
\hline Driver training & $\begin{array}{l}\text { 1. Held new hire safety training with the Safety Manager to review HOS regulations, introduce safety } \\
\text { expectations and policies, and provide an overview of the safety technologies. } \\
\text { 2. All new drivers were mentored by an experienced driver for several weeks to answer questions, } \\
\text { provide tips, and help the new driver with any issues. } \\
\text { 3. Held biannual in-person safety meetings to review recent crash and incident data. Example videos } \\
\text { from the VDMS were discussed to point out suggestions and recognition for safe driving. } \\
\text { 4. Offered individual coaching based on VDMS data. }\end{array}$ \\
\hline Safety culture & $\begin{array}{l}\text { 1. Created a family environment where drivers offered to assist other drivers who needed help. All } \\
\text { employees knew each driver by name. } \\
\text { 2. Had top management support. } \\
\text { 3. Made Safety Director available } 24 \text { h a day for assistance. }\end{array}$ \\
\hline $\begin{array}{l}\text { Dispatching and } \\
\text { scheduling }\end{array}$ & $\begin{array}{l}\text { 1. Prioritized weekly home time for all drivers. } \\
\text { 2. Allowed drivers to begin routes from home. } \\
\text { 3. Scheduled routes based on ELD data to match drivers' preferred sleep schedules. }\end{array}$ \\
\hline Safety technologies & $\begin{array}{l}\text { 1. In } 2018 \text {, equipped all trucks with VDMS. } \\
\text { 2. Equipped all trucks with speed limiters. }\end{array}$ \\
\hline Vehicle maintenance & 1. No new strategies. \\
\hline
\end{tabular}

\subsection{Haddon Matrix of All Suggested Strategies}

A total of 64 distinct safety countermeasures were mentioned across the nine case studies. These safety countermeasures were those mentioned by the fleets as critical to improving or maintaining their safety performance. These are likely not all the safety program or initiatives the fleets implemented; however, these are the ones the fleets noted as being important to reducing their crashes, violations, or claims.

Each of these safety countermeasures was grouped into a $3 \times 4$ Haddon Matrix (see Table S1). The Haddon Matrix includes identifying pre-crash, at the scene, and post-crash crash safety initiatives, and identifying if they focus on the vehicle, people, environment, or culture. Many of the identified countermeasures could fall into multiple areas (i.e., nearly all countermeasures rely on a strong safety culture); however, these were categorized based on the primary target (i.e., the vehicle, individual, environment, or management). As shown in Table S1, 55 of the $64(85.9 \%)$ safety countermeasures fell into the pre-crash category.

\section{Discussion}

This study attempted to identify the strategies that fleets used to successfully improve their safety performance and, in some cases, helped the fleet avoid losing their insurance or federal authority to operate. Examining the results of the case studies highlights several important conclusions. First, there was no single strategy to successfully reduce crashes and improve safety. Instead, each fleet examined their operation and policies to develop a comprehensive, tailored approach to improve safety. Although the specific strategies varied across fleets, all of the fleets focused on safety-focused hiring criteria, driver training for new 
and existing drivers, and implementing policies and programs to improve safety culture. This comprehensive approach to improve safety supports previous research $[2,3,14,15]$.

Second, results from this study showed a few key strategies that carriers should focus on when attempting to improve their safety performance. For instance, six of the nine carriers indicated that an improved safety culture was critical to their success. This finding aligns with the results reported in Bergoffen et al. [15] and Corsi and Barnard [3], who previously found that management culture was significantly related to safety. Additionally, the strategies used by the fleets to improve safety performance closely matched the management best practices described in Short et al. [17]. These practices involve generating support and commitment from top management, generating buy-in from drivers, creating a family environment, holding all employees and departments accountable for their role in driver safety, and using reward and recognition programs.

Finally, it was apparent that vehicle safety technology played an important role in improving the participating fleets' safety performance. Eight of the nine carriers implemented some type of safety technology, and six of the nine carriers indicated that the safety technology was critical to the successful improvement in safety performance. These results support findings from previous research that safety technologies were effective at preventing crashes [25-31]. In fact, some of the fleets that participated in this study found significant reductions in crashes following the deployment of a safety technology. For example:

- Fleet A experienced a 56\% reduction in preventable rear-end crashes after implementing AEB.

- Fleet B reported a 32\% reduction in FMCSA-reportable crash rate after implementing a suite of advanced safety technologies.

- Fleet $C$ used AEB along with a telematics device and experienced a $75 \%$ reduction in preventable crashes.

- Fleet D eliminated rear-end crashes and rollovers with AEB and roll stability control on trailers.

- Fleet E reported a 36\% reduction in FMCSA-reportable crash rates after implementing a suite of safety technologies.

- Fleet $\mathrm{F}$ noticed a $66 \%$ reduction in their FMCSA-reportable crash rate after implementing VDMS and AEB.

These results suggest that safety technologies have a positive return on investment, which supports the findings from Belzowski et al. [25] and Medina-Flintsch et al. [32]. Each of the fleets that used an advanced safety technology to improve safety believed they experienced a positive return on investment and continued purchasing trucks with the advanced safety technologies.

However, fleets did experience some challenges and barriers when implementing some of these safety-improvement strategies. Some fleets indicated challenges associated with using strict hiring criteria. Fleet $\mathrm{B}$ and Fleet $\mathrm{F}$ mentioned difficulties finding qualified drivers after implementing strict hiring criteria based on potential employees' past safetyperformance. Fleet B overcame this challenge by working closely with recruiters to increase advertising and targeted recruitment efforts. Additionally, Fleet B found that some of their existing drivers did not meet these stricter hiring criteria, which required these existing drivers to complete additional training or face termination. However, all open driver positions were filled within 8 months of revising the hiring criteria. Fleet $F$ used a different strategy to address the challenges associated with strict hiring criteria. They focused their efforts on driver retention. They adjusted driver pay from mileage to hourly, offered retention bonuses, annual pay raises, and driver referral bonuses.

The other common barrier discussed by many fleets was driver resistance to the safety technologies. Drivers at many of the carriers that implemented AEB were initially resistant to the technology as they did not like the idea of losing control of the vehicle. However, all the fleets indicated that resistance diminished as soon as drivers experienced the technology working to prevent a crash and understood its benefits. This also supports the results in 
Hickman et al. [36], where drivers suggested that experiencing safety technologies helped to generate buy-in. Fleet $\mathrm{B}$ also experienced challenges associated with the older generation of LDW. Initially, the technology was an annoyance to drivers due to excessive false alerts, and the fleet decided to disable it. However, Fleet B pilot tested a newer generation of LDW and found that it was significantly better at limiting false alerts. They decided to equip all new trucks with the latest generation of LDW. Finally, fleets that implemented a VDMS experienced initial resistance from drivers. Fleets were able to overcome this resistance by being open and honest about the reasons for implementing the system, showing drivers the pilot test data (which revealed the reductions in risky driving), actively listening to driver concerns about privacy, and using early and frequent communications to address driver feedback.

\section{Limitations}

Although this study captured important information related to strategies fleets used to improve safety performance, there are a few limitations. First, this study was not able to quantify the safety improvements caused by specific strategies. Rather, this qualitative study could only compare and contrast the strategies implemented by a diverse group of CMV fleets. Second, because most of the CMV fleets were medium to large CMV fleets, the results may not generalize to small fleets (i.e., 1-5 power units). Small fleets may have different experiences; thus, the strategies highlighted in this study may not be appropriate or reflective of their experiences. Finally, all nine fleets that participated in this study were for hire; no private fleets participated. It is possible that private fleets may have additional strategies that may be effective at improving safety.

\section{Conclusions}

Poor safety performance can have significant consequences for fleets. Not only do CMV crashes often result in injury or significant property damage, poor safety records often lead to increased insurance rates, the loss of insurance, and significant liability. Thus, finding strategies to successfully improve safety is important; however, many fleets may not know what their peers have done to successfully improve safety. This study was designed to identify strategies that fleets have used to reduce crash rates and improve CSA scores. Results from this study support previous research showing the importance of a comprehensive approach to safety with a focus on improving safety culture and using safety technologies. Strategies included ensuring leadership's commitment to safety performance, strictly adhering their hiring criteria, implementing driver training and education, emphasizing driver-focused programs, and equipping the vehicles with safety technologies designed to reduce crashes.

Supplementary Materials: The following are available online at https:/ /www.mdpi.com/article/10 .3390/safety8010002/s1, Table S1: Haddon Matrix of CMV Safety Best Practices.

Author Contributions: Conceptualization: M.C.C. and J.S.H.; methodology: M.C.C. and J.S.H.; formal analysis: M.C.C.; writing —original draft preparation: M.C.C.; writing-review and editing: J.S.H. and R.J.H.; funding acquisition: M.C.C. and J.S.H.; and project administration: M.C.C. All authors have read and agreed to the published version of the manuscript.

Funding: This research was funded by the National Surface Transportation Safety Center for Excellence, project number 451505.

Institutional Review Board Statement: The study was conducted according to the guidelines of the Declaration of Helsinki and approved by the Institutional Review Board of Virginia Tech (IRB number 18-350, 9 April 2018).

Informed Consent Statement: Informed consent was obtained from all subjects involved in the study. 
Data Availability Statement: Raw data cannot be made public as they would identify the participants and would violate the IRB agreement.

Conflicts of Interest: The authors declare no conflict of interest.

\section{References}

1. Federal Motor Carrier Safety Administration. Status of High-Risk Carrier Investigations; Federal Motor Carrier Safety Administration: Washington, DC, USA, 2021.

2. $\quad$ Knipling, R.R.; Hickman, J.S.; Bergoffen, G. Synthesis 1: Effective Commercial Truck and Bus Safety Management Techniques; Transportation Research Board of the National Academies: Washington, DC, USA, 2003.

3. Corsi, T.M.; Barnard, R.E. Best Highway Safety Practices: A Survey about Safety Management Practices among the Safest Motor Carriers; Federal Motor Carrier Safety Administration: Washington, DC, USA, 2003.

4. $\quad$ Stock, D. I-95 Corridor Coalition Field Operational Test 10: Coordinated Safety Management; Volume I: Best Practices in Motor Carrier Safety Management; Penn State University: State College, PA, USA, 2001.

5. Belzer, M.H.; Rodriquez, D.; Sedo, S.A. Paying for Safety: An Economic Analysis of the Effect of Compensation on Truck Driver Safety; Federal Motor Carrier Safety Administration: Washington, DC, USA, 2002.

6. Faulkiner, M.R.; Belzer, M.H. Returns to compensation in trucking: Does safety pay? Econ. Labour Relat. Rev. 2019, 30, 262-284. [CrossRef]

7. Kudom, T.; Belzer, M.H. The association between truck driver compensation and safety performance. Saf. Sci. 2019, 120, 447-455. [CrossRef]

8. $\quad$ Knipling, R.R.; Boyle, L.N.; Hickman, J.S.; York, J.S.; Daecher, C.; Olsen, E.C.B.; Prailey, T.D. CTBSSP Synthesis 4: Individual Differences and the "High-Risk" Commercial Driver; Transportation Research Board of the National Academies: Washington, DC, USA, 2004.

9. Camden, M.C.; Hickman, J.S.; Soccolich, S.A.; Hanowski, R.J. Reducing risky driving: Assessing the impacts of an automaticallyassigned, targeted web-based instruction program. J. Saf. Res. 2019, 70, 105-115. [CrossRef] [PubMed]

10. Hickman, J.S.; Knipling, R.R.; Hanowski, R.J.; Wiegand, D.M.; Inderbitzen, R.E.; Bergoffen, G. CTBSSP 11: Impact of Behavior-Based Safety Techniques on Commercial Motor Vehicle Drivers; Transportation Research Board of the National Academies of Science: Washington, DC, USA, 2007.

11. Andreis, F.; Kompier, M.A.J.; Smulders, P.G.W. Do you think your health or safeties are at risk because of your work? A large European study on psychological and physical work demands. Work. Stress 1996, 10, 104-118. [CrossRef]

12. Cheyne, A.; Oliver, A.; Tomas, J.M.; Cox, S. The architecture of employee attitudes to safety in the manufacturing sector. Pers. Rev. 2002, 31, 649-670. [CrossRef]

13. Harvey, J.; Erdos, G.; Bolam, H.; Cox, M.A.A.; Kennedy, J.N.P.; Gregory, D.T. An analysis of safety culture attitudes in a highly regulated environment. Work. Stress 2002, 16, 18-36. [CrossRef]

14. Arboleda, A.; Morrow, P.C.; Crum, M.R.; Shelley, M.C. Management practices as antecedents of safety culture within the trucking industry: Similarities and differences by hierarchical level. J. Saf. Res. 2003, 34, 189-197. [CrossRef]

15. Bergoffen, G.; Short, J.; Inderbitzen, B.; Daecher, C. CTBSSP Synthesis 12: Commercial Motor Vehicle Carrier Safety Management Certification; Transportation Research Board of the National Academies of Science: Washington, DC, USA, 2007.

16. Nævestad, T.-O.; Hesjevoll, I.S.; Phillips, R.O. How can we improve safety culture in transport organizations? A review of intervention, effects, and influencing factors. Transp. Res. Part F Traffic Psychol. Behav. 2018, 54, 28-46. [CrossRef]

17. Short, J.; Boyle, L.; Shackelford, S.; Inderbitzen, B.; Bergoffen, G. CTBSSP Synthesis 14: The Role of Safety Culture in Preventing Commercial Motor Vehicle Crashes; Transportation Research Board of the National Academies: Washington, DC, USA, 2007.

18. Hickman, J.S.; Mabry, J.E.; Marburg, L.; Guo, F.; Huiying, M.; Hanowski, R.; Whiteman, J.; Herbert, W. Commercial Driver Safety Risk Factors (CDSRF); Report No. FMCSA-RRR-17-014; Federal Motor Carrier Safety Management System: Washington, DC, USA, 2020.

19. Federal Motor Carrier Safety Administration. Report to Congress on the Large Truck Crash Causation Study; Report No. MC-R/MCRRA; Federal Motor Carrier Safety Administration: Washington, DC, USA, 2006.

20. National Transportation Safety Board. Safety Study: Fatigue, Alcohol, Other Drugs, and Medical Factors in Fatal-to-the-Driver Heavy Truck Crashes; Report No. NTSB/SS-90/02; National Transportation Safety Board: Washington, DC, USA, 1990.

21. Pratt, S.G. Work-Related Roadway Crashes: Challenges and Opportunities for Prevention; NIOSH Publication No. 2003-119; National Institutes for Occupational Safety and Health: Washington, DC, USA, 2003.

22. Heitmann, A.; Guttkun, R.; Croke, D.; Moore-Ede, M. Innovative fatigue management approach in the trucking industry. In Proceedings of the Third International Driving Symposium on Human Factors in Driver Assessment, Training and Vehicle Design, Rockport, ME, USA, 27-30 June 2005.

23. Knipling, R.R.; Bergoffen, G. CTBSSP 20: Potential Safety Benefits of Motor Carrier Operational Efficiencies; Transportation Research Board of the National Academies: Washington, DC, USA, 2011.

24. Hickman, J.S.; Guo, F.; Camden, M.C.; Dunn, N.J.; Hanowski, R.J. An observational study of the safety benefits of electronic logging devices using carrier-collected data. Traffic Inj. Prev. 2017, 18, 312-317. [CrossRef] [PubMed] 
25. Belzowski, B.M.; Blower, D.; Woodrooffee, J.; Green, P.E. Tracking the Use of Onboard Safety Technologies Across the Truck Fleet; Report No. UMTRI 2009-22; University of Michigan Transportation Research Institute: Ann Arbor, MI, USA, 2009.

26. Camden, M.C.; Medina-Flintsch, A.; Hickman, J.S.; Hanowski, R.J.; Tefft, B. Do the benefits outweigh the costs? Societal benefit-cost analysis of three large truck safety technologies. Accid. Anal. Prev. 2018, 121, 177-184. [CrossRef] [PubMed]

27. Hickman, J.S.; Guo, F.; Camden, M.C.; Hanowski, R.J.; Medina, A.; Mabry, J.E. Efficacy of roll stability and lane departure warning systems using carrier-collected data. J. Saf. Res. 2015, 52, 59-63. [CrossRef] [PubMed]

28. Toeh, E.R. Effectiveness of front crash prevention systems in reducing large truck real-world crash rates. Traffic Inj. Prev. 2021, 22, 284-289. [CrossRef] [PubMed]

29. Hickman, J.S.; Hanowski, R.J. Evaluating the Safety Benefits of a Low-Cost Driving Behavior Management System in Commercial Vehicle Operations; Report No. FMCSA-RRR-10-033; Federal Motor Carrier Safety Administration: Washington, DC, USA, 2010.

30. Bell, J.L.; Taylor, M.A.; Chen, G.-X.; Kirk, R.D.; Leatherman, E.R. Evaluation of an in-vehicle monitoring system (IVMS) to reduce risky driving behaviors in commercial drivers: Comparison of in-cab warning lights and supervisory coaching with videos of driving behaviors. J. Saf. Res. 2017, 60, 125-136. [CrossRef] [PubMed]

31. Boyle, L.N.; Guo, E.H.; Hammond, R.L.; Hanowski, R.J.; Soccolich, S.A. Performance Assessment of an Onboard Monitoring System for Commercial Motor Vehicle Drivers: A Field Operational Test; Report No. FMCSA-RRR-15-019; Federal Motor Carrier Safety Administration: Washington, DC, USA, 2016.

32. Medina-Flintsch, A.; Hickman, J.S.; Guo, F.; Camden, M.C.; Hanowski, R.J.; Kwan, Q. Benefit-cost analysis of lane departure warning and roll stability control in commercial vehicles. J. Saf. Res. 2017, 62, 73-80. [CrossRef] [PubMed]

33. Murray, W.; Newnam, S.; Watson, B.; Davey, J.; Schonfeld, C. Evaluating and Improving Fleet Safety in Australia; Australian Transport Safety Bureau: Canberra, ACT, Australia, 2003.

34. Murray, W.; Ison, S.; Gallemore, P.; Nijjar, H.S. Effective occupational road safety programs: A case study of Wolseley. Transp. Res. Rec. 2009, 2096, 55-64. [CrossRef]

35. Ritchie, J.; Spencer, L.; O'Conner, W. Carrying out qualitative analysis. In Qualitative Research Practice; Ritchie, J., Lewis, J., Eds.; Sage: London, UK, 2003.

36. Hickman, J.S.; Guo, F.; Camden, M.C.; Medina, A.; Campbell, J.L.; Hanowski, R.J.; Mabry, E.; Brown, J.; Richard, C.; Salyer, D. Onboard Safety System Effectiveness Evaluation Final Report; Report No. FMCSA-RRT-12-012; Federal Motor Carrier Safety Administration: Washington, DC, USA, 2013. 